\title{
The role of a chemical loop in removal of hazardous contaminants from coke oven wastewater during its treatment
}

https://doi.org/10.1515/chem-2019-0142

received December 3, 2018; accepted October 16, 2019.

\begin{abstract}
Coke oven liquor is one of the most contaminated liquid streams generated by the coal processing industry, thus its proper treatment and utilization is crucial for sustainable and environmentally neutral plant operation. The conventional wastewater treatment process comprises of chemical and biological processes. Within the current research the detailed role of chemical treatment is described. Commercially available iron-based coagulants (PIX100, PIX100COP, PIX113, PIX116) were tested to understand their removal efficiency and impact on the stream parameters. The influence of iron dose in the range of $300-500 \mathrm{mgFe} / \mathrm{L}$ on the process performance was also examined.

It was found that the main role of chemical treatment was to bind toxicants harmful to activated sludge microorganisms, i.e. free and complex cyanides and sulphides. Among the tested iron-based conventional coagulants ferrous salts were more efficient than ferric salts. It was also observed that efficiency of the process strongly depended on wastewater properties (especially in regard to $\mathrm{pH}$, which should be in the range of 9-10) and the coagulant selection needed to be done individually for a given wastewater type. The removal rates of particular contaminants were diversified and for free cyanides, complex cyanides and sulphides they were in the range of $23-91 \%,-156-77 \%$ and $-357-98 \%$, respectively. The expected, simultaneous removal of chemical oxygen demand (COD) during the treatment was not observed and even the parameter value increased after the process due to probable formation of compounds less vulnerable to oxidation.
\end{abstract}

\footnotetext{
*Corresponding author: Anna Kwiecińska-Mydlak, Institute for Chemical Processing of Coal, Zamkowa 1, 41-800 Zabrze, Poland, E-mail: akwiecinska@ichpw.pl

Marcin Sajdak, Katarzyna Rychlewska, Jan Figa, Institute for Chemical Processing of Coal, Zamkowa 1, 41-800 Zabrze, Poland
}

Keywords: coke oven wastewater; coagulation; cyanides; sulphides; treatment.

\section{Introduction}

Coke is produced during pyrolysis of coal carried out in coke oven batteries comprised of special chambers called coke ovens operated at temperatures reaching up to $1,200^{\circ} \mathrm{C}$. During the process, volatile compounds are released from coal forming coke oven gas, whereas the remaining mass, i.e. coke, contains mainly carbon and non-volatile minerals [1]. The scheme of coke production at a typical coke oven plant is shown in Figure 1.

The coke is mainly used in the iron and steel industry and its worldwide annual production in the last decade varied from 650 to $700 \mathrm{Mt}$ [2]. The second product of coal pyrolysis, i.e. coke oven gas, after the treatment and recovery of so called coal derivatives, i.e. tars and benzol, is used for heating of coke ovens and for other energy generation purposes, usually inside the plant. The processing of coke oven gas starts with cooling, during which condensation of organic compounds and water vapor, which washes out some inorganic gas components like ammonia, hydrogen cyanide and hydrogen sulphide from the gas, occurs [3,4]. The condensate, known also as coal liquor, is firstly introduced to the tars separation department, in which water insoluble organic compounds are separated and directed to further processing. The remaining aqueous phase, from this stage called ammoniacal liquor, is used for flushing cooling of coke oven gas and, in case of plants operated with ammoniacal method of gas desulphurization, is involved in further washing of hydrogen sulphide from the gas [5-7]. However, the amount of ammoniacal liquor is always higher than the amount required for technological purposes. This excess liquor is directed to ammonia stripping carried out at alkaline conditions, and the stripping column downstream is the influent of coke oven wastewater 


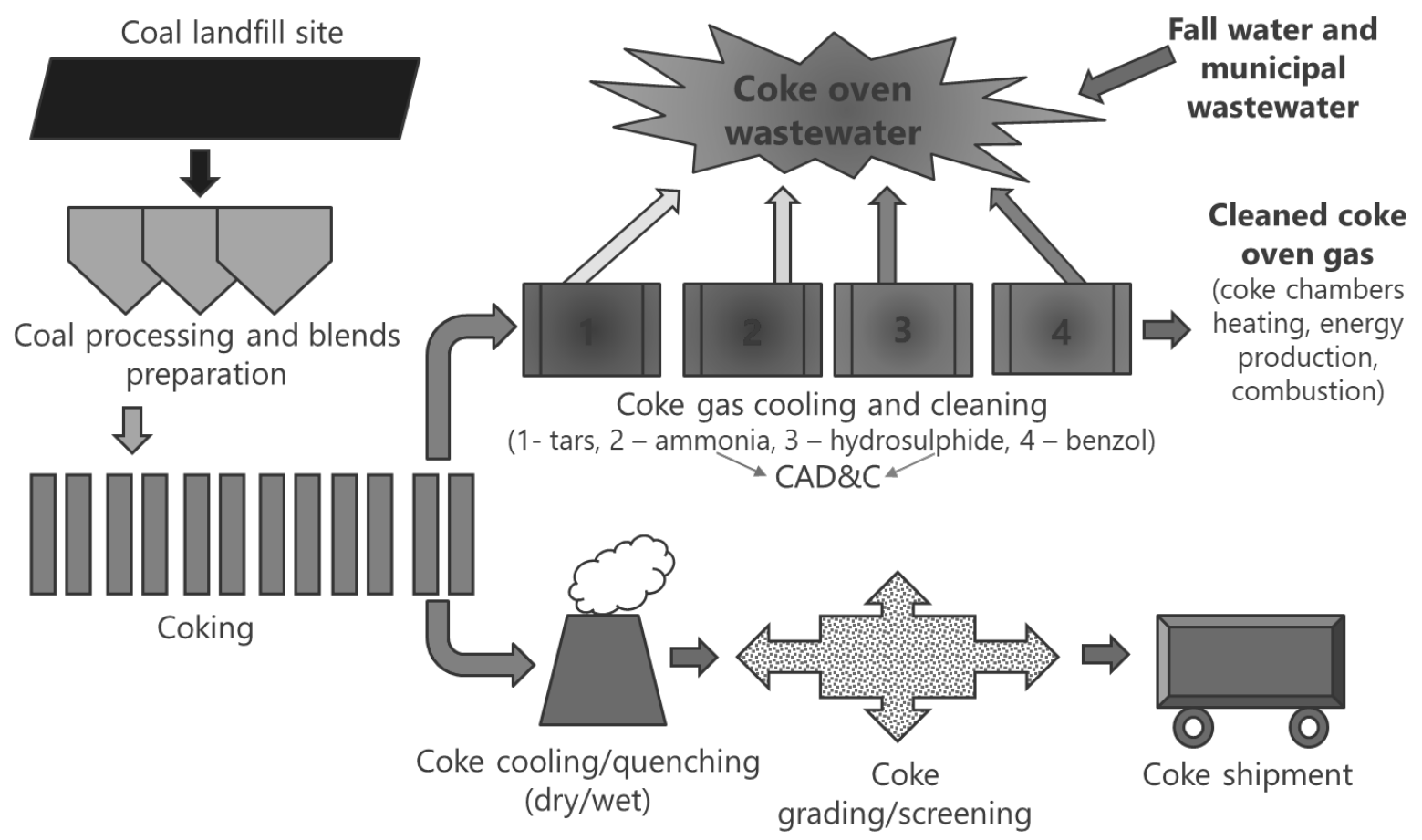

Figure 1: The scheme of coke production at a coke oven plant.

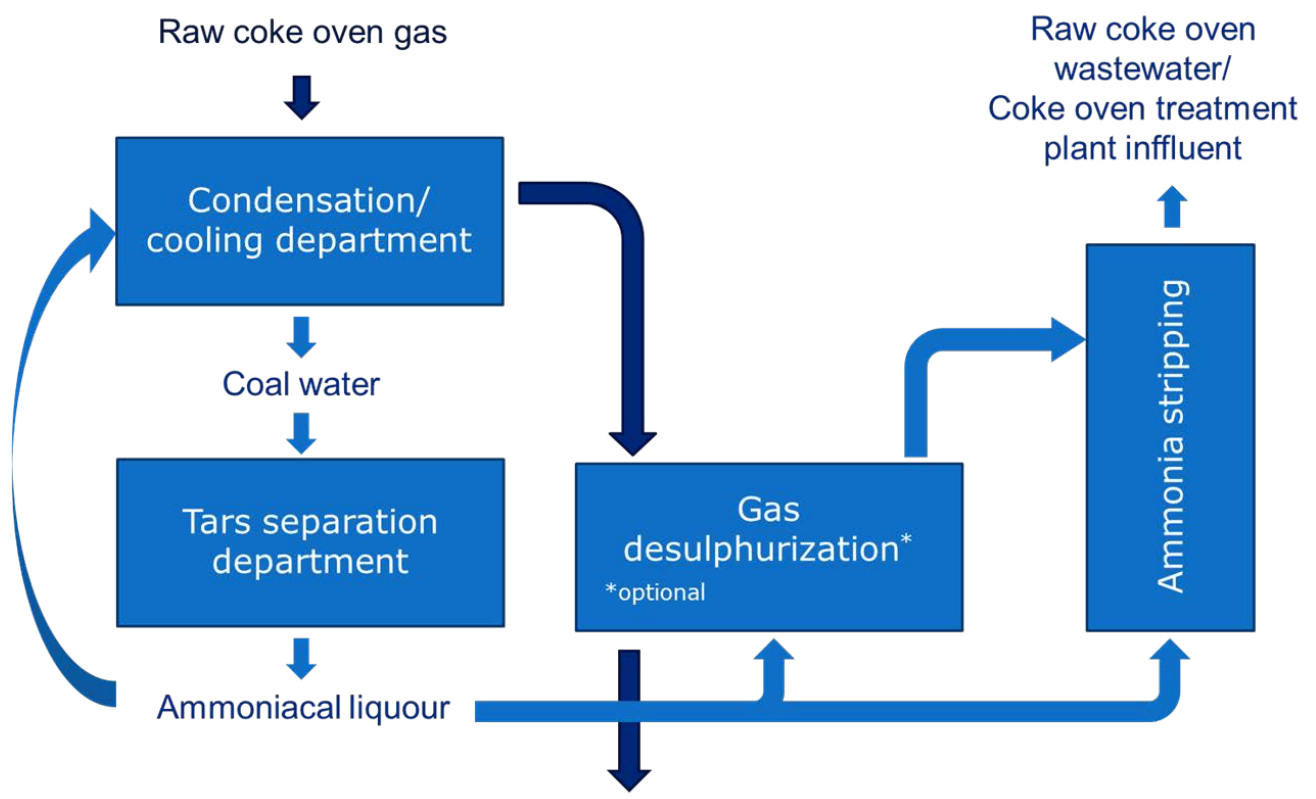

Coke oven gas to BTX recovery

Figure 2: The scheme of formation of coke oven wastewater.

treatment plant [8-10]. The scheme of formation of coke oven wastewater is presented in Figure 2.

It is assumed that at a typical plant for every 1 ton of coke produced $1-1.5 \mathrm{~m}^{3}$ of coke oven wastewater is generated [11-13]. The qualitative composition of coke oven wastewater is well recognized whereas ranges of concentrations of particular compounds present in the stream vary depending on many factors, among which the coal quality and coke oven gas processing methods are the most important. In Table 1 the typical composition of 
Table 1: Typical composition of raw coke oven wastewater.

\begin{tabular}{lll}
\hline Parameter & Unit & Concentration range \\
\hline $\mathrm{pH}$ & - & $7-9.5$ \\
Specific conductivity & $\mathrm{\mu S} / \mathrm{cm}$ & $5,000-12,500$ \\
$\mathrm{COD}$ & $\mathrm{mgO}_{2} / \mathrm{L}$ & $2,000-6,500$ \\
$\mathrm{BOD}_{5}$ & $\mathrm{mgO}_{2} / \mathrm{L}$ & $800-3,000$ \\
PAHs & $\mathrm{mg} / \mathrm{L}$ & $5-150$ \\
Sulphides & $\mathrm{mg} / \mathrm{L}$ & $10-50$ \\
Cyanides & $\mathrm{mg} / \mathrm{L}$ & $5-20$ \\
Thiocyanates & $\mathrm{mg} / \mathrm{L}$ & $50-420$ \\
Phenols & $\mathrm{mg} / \mathrm{L}$ & $500-1,500$ \\
Ammonia & $\mathrm{mg} / \mathrm{L}$ & $50-200$ \\
Chlorides & $\mathrm{mg} / \mathrm{L}$ & $2,500-3,500$ \\
Sulphates & $\mathrm{mg} / \mathrm{L}$ & $900-1,200$ \\
\hline
\end{tabular}

a raw coke oven wastewater (i.e. ammoniacal liquor after stripping) is presented.

A coke oven wastewater treatment plant is usually arranged in a conventional way, i.e. firstly the physicochemical treatment of the stream is performed and it is followed by biological removal of ammonia (by nitrification/denitrification) and organic compounds (phenols) [14-17]. The chemical treatment is based on a coagulation process in which iron containing coagulants (ferrous/ferric chloride/sulphate) are used which results in the occurrence of following reactions [7-8, 11-12]:

$$
\begin{aligned}
\mathrm{Fe}^{+2}+\mathrm{HS}^{-} & \rightarrow \mathrm{FeS} \downarrow+\mathrm{H}^{+} \\
\mathrm{FeS}+\mathrm{HS}^{-} & \rightarrow \mathrm{FeS}_{2}+\mathrm{H}^{+} \\
\mathrm{Fe}^{+2}+6 \mathrm{CN} & \rightarrow \mathrm{Fe}(\mathrm{CN})_{6}^{-4} \\
\mathrm{Fe}^{+3}+6 \mathrm{CN}^{-4} & \rightarrow \mathrm{Fe}(\mathrm{CN})_{6}^{-3} \\
4 \mathrm{Fe}^{+3}+3 \mathrm{Fe}(\mathrm{CN})_{6}^{-4} & \rightarrow \mathrm{Fe}_{4}\left[\mathrm{Fe}(\mathrm{CN})_{6}\right]_{3} \downarrow \\
\mathrm{Fe}^{+3}+\mathrm{Fe}(\mathrm{CN})_{6}^{-3} & \left.\rightarrow \mathrm{Fe}^{-3} \mathrm{Fe}(\mathrm{CN})_{6}\right] \downarrow \\
2 \mathrm{Fe}^{+2}+\mathrm{Fe}(\mathrm{CN})_{6}^{-4} & \rightarrow \mathrm{Fe}_{2}\left[\mathrm{Fe}(\mathrm{CN})_{6}\right] \downarrow \\
3 \mathrm{Fe}^{+2}+2 \mathrm{Fe}(\mathrm{CN})_{6}^{-3} & \rightarrow \mathrm{Fe}_{3}\left[\mathrm{Fe}(\mathrm{CN})_{6}\right]_{2} \downarrow
\end{aligned}
$$

(1) $1 \mathrm{~L}$ of coke oven wastewater was introduced to the

The biological treatment usually comprises of nitrification and denitrification processes which enable the efficient removal of ammonia and phenols. For better performance laboratory coagulation reactor of total volume of $1.3 \mathrm{~L}$

of the treatment, preliminary ammonification dedicated to decomposition of nitrogen-containing organic compounds and thiocyanates may be used, while for the improvement of COD decrease separate biological reactors for organic compounds decomposition may be installed. The exemplary schemes of different coke oven wastewater treatment plant arrangements are shown in Figure 3.

Within the current research the role and the efficiency of chemical treatment carried out with the use of commercially available iron-based coagulants was examined. The impact of the coagulant type and dose on cyanides, sulphides, COD, $\mathrm{pH}$ and salinity of coke oven wastewater compared to the raw stream parameters was investigated.

\section{Methods}

\subsection{Feedstock characteristics}

Four types of commercially available coagulants based on different iron salts were used to treat raw coke oven wastewaters of different parameters sampled at three coke oven plants of diversified production profile. In Table 2 , the characteristic of the coagulants is given and the parameters of raw coke oven wastewaters (COW) used in the experiments are presented in Table 3.

\subsection{Experimental procedure} and mixed for 1 minute at $50 \mathrm{rpm}$ using a magnetic stirrer. Next, the proper dose of coagulant corresponding to the desired amount of iron was introduced and the system was vigorously mixed for 1 minute at $200 \mathrm{rpm}$. All coagulants were tested at three different doses, recalculated to the amount of iron introduced to the system, i.e. 300, 400, $500 \mathrm{mgFe} / \mathrm{L}$. Next, the mixing was slowed down to 50 rpm and the system was mixed at such conditions for 5 minutes. Finally, the mixture was left for 30 minutes for flocculation and settling and after this time the portion of supernatant was collected for analysis.

\subsection{Analytical procedures}

The content of free cyanides ( $\mathrm{CN}$ free) and sulphides was determined using ion chromatography with pulsed 


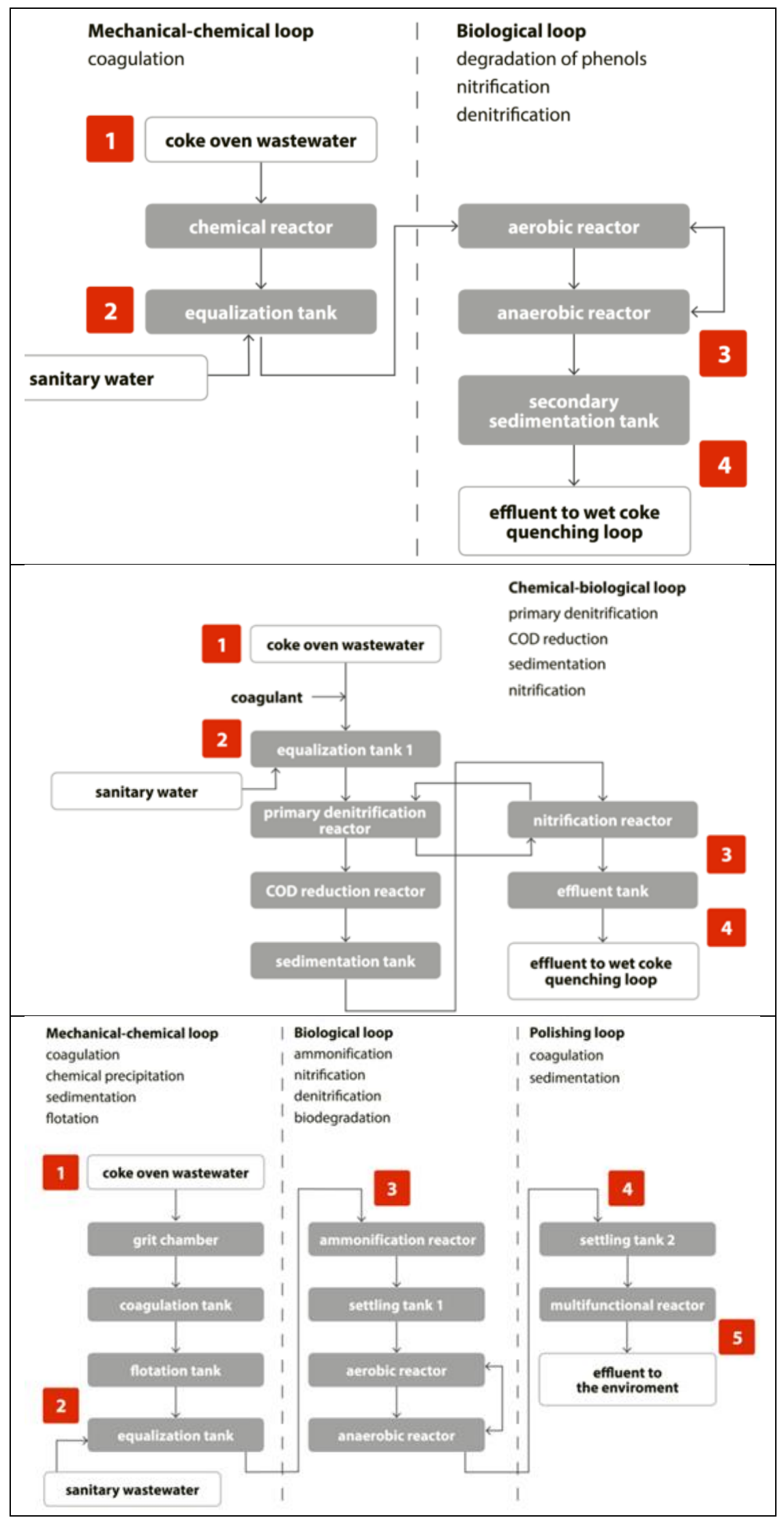

Figure 3: Different arrangements of coke oven wastewater treatment plants. 
Table 2: The characteristics of coagulants used in the research.

\begin{tabular}{llllll}
\hline Coagulant & Trade name & $\mathrm{Fe}^{2+}$ content & $\mathrm{Fe}_{\text {tot }}$. content & $\mathrm{pH}$ & Free acid \\
\hline $\mathrm{FeCl}_{2}$ & PIX100 & $10.3 \pm 0.7 \%$ & $10.3 \pm 0.7 \%$ & $<1$ & $2 \div 4 \%$ \\
$\mathrm{FeSO}_{4}$ & PIX100COP & $6.0 \pm 1.0 \%$ & $6.0 \pm 1.0 \%$ & $\sim 1$ & $1.5 \div 2.5 \%$ \\
$\mathrm{Fe}_{2}\left(\mathrm{SO}_{4}\right)_{3}$ & PIX113 & $0.4 \pm 0.3 \%$ & $11.8 \pm 0.4 \%$ & $<1$ & $-0.5 \div 0.0 \%$ \\
$\mathrm{FeCl}_{3}$ & PIX116 & max. $0.5 \%$ & $11.5 \pm 0.5 \%$ & $<1$ & $0.5 \div 3.0 \%$ \\
\hline
\end{tabular}

Table 3: Characteristics of coke oven wastewater used in the research.

\begin{tabular}{lllll}
\hline Parameter & Unit & COW1 & COW2 & COW3 \\
\hline $\mathrm{pH}$ & - & 9.84 & 9.37 & 12.25 \\
Conductivity & $\mathrm{HS} / \mathrm{cm}$ & 10,423 & 8,729 & 14,738 \\
Redox potential & $\mathrm{mV}$ & -135.2 & -107.5 & -263.1 \\
Free cyanides & $\mathrm{mg} / \mathrm{L}$ & 7.79 & 6.17 & 9.29 \\
Complex cyanides & $\mathrm{mg} / \mathrm{L}$ & 7.97 & 1.20 & 7.10 \\
Sulphides & $\mathrm{mg} / \mathrm{L}$ & 9.39 & 2.20 & 9.97 \\
COD & $\mathrm{mgO} / \mathrm{L}$ & 3,649 & 4,125 & 5,370 \\
Chlorides & $\mathrm{mg} / \mathrm{L}$ & 2,700 & 1,794 & 2,698 \\
Sulphates & $\mathrm{mg} / \mathrm{L}$ & 135 & 255 & 293 \\
\hline
\end{tabular}

amperometric detection (IC-PAD). The standard procedure included isocratic separation of both anions in 15 minutes using Thermo-Scientific IonPac AS7 $(250 \mathrm{~mm} \times 2 \mathrm{~mm})$ analytical column and guard $(50 \mathrm{~mm} \times 2 \mathrm{~mm})$ column set with $600 \mathrm{mM}$ degassed sodium hydroxide at a flow rate of $0.250 \mathrm{~cm}^{3} / \mathrm{min}$ and column temperature of $30^{\circ} \mathrm{C}$. Analytes were detected by $\mathrm{PAD}$ using a silver working electrode, combined with $\mathrm{pH}-\mathrm{Ag} / \mathrm{AgCl}$ reference electrode in $\mathrm{AgCl}$ mode. The PAD waveform used for these experiments was a three-potential waveform optimized for silver electrodes and cyanide, sulphide, iodide, and thiosulphate anions in a hydroxide eluent. The method was suitable for cyanides and sulphides concentrations in the range 0.05 to 5 $\mathrm{mg} / \mathrm{L}$. Due to the complexity of the coke oven wastewater matrix, the analytical samples were firstly diluted with eluate solution in order to assure complete dissociation of cyanide and sulphide salts and allowed analysis in the desired detection range. Determination of total cyanide concentration comprised of thermal distillation in acidic conditions with a copper catalyst, during which evolved hydrogen cyanide was collected in alkaline solution placed in gas washers. The obtained analytical samples were then introduced to IC-PAD analysis and the procedure used for free cyanides detection was followed. The content of complex cyanide ( $\mathrm{CN}$ complex) was calculated as the difference between total and free cyanides concentration. The amounts of chlorides and sulphates were analyzed using ion chromatography with conductometric detection (IC-CD) and the chemical oxygen demand (COD) was determined by a spectrophotometric method preceded with sample mineralization with potassium dichromate according to $\mathrm{HACH}$ procedure. $\mathrm{pH}$ and conductivity of process streams were measured with the use of dedicated measuring probes.

Ethical approval: The conducted research is not related to either human or animal use.

\section{Results and discussion}

\subsection{Free cyanides}

In Figures 4-6 the impact of coagulant type and dose on the final concentration of free cyanides measured in particular coke oven wastewater is shown. The desired free cyanide concentration permitted for biological loop influent was established at $0.5 \mathrm{mg} / \mathrm{L}$ (standard). 


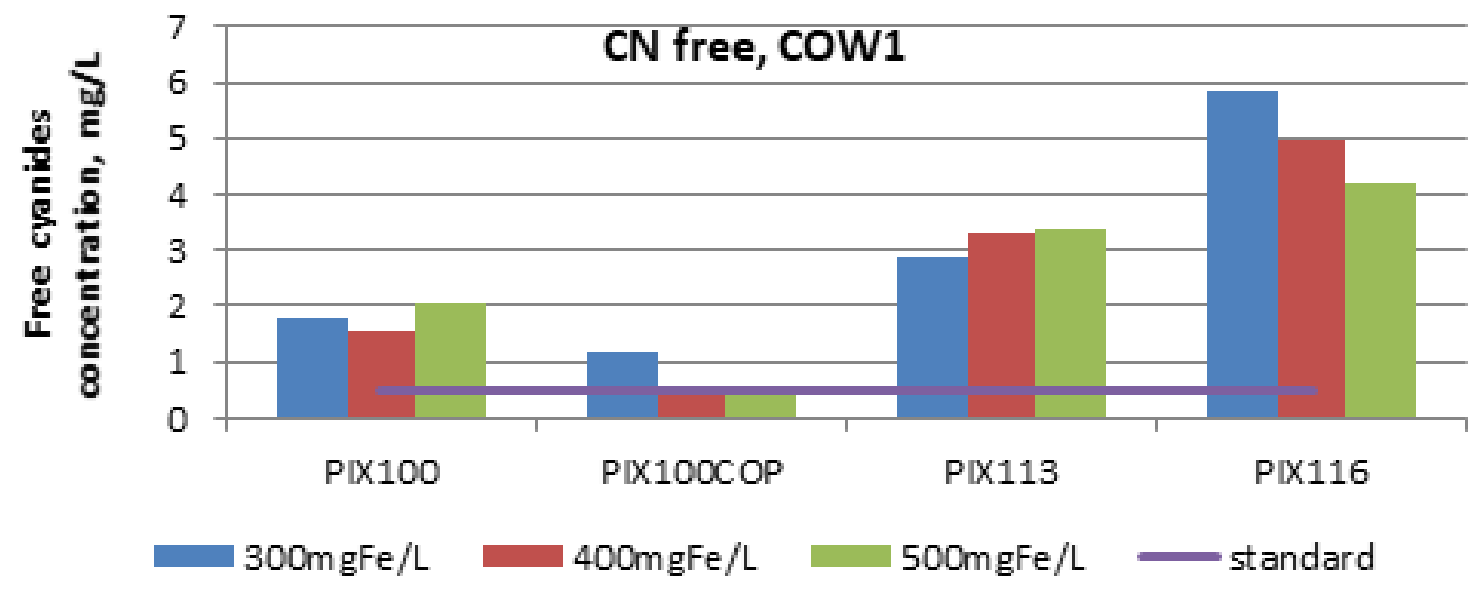

Figure 4: Final concentration of free cyanides in coke oven wastewater 1 (COW1).

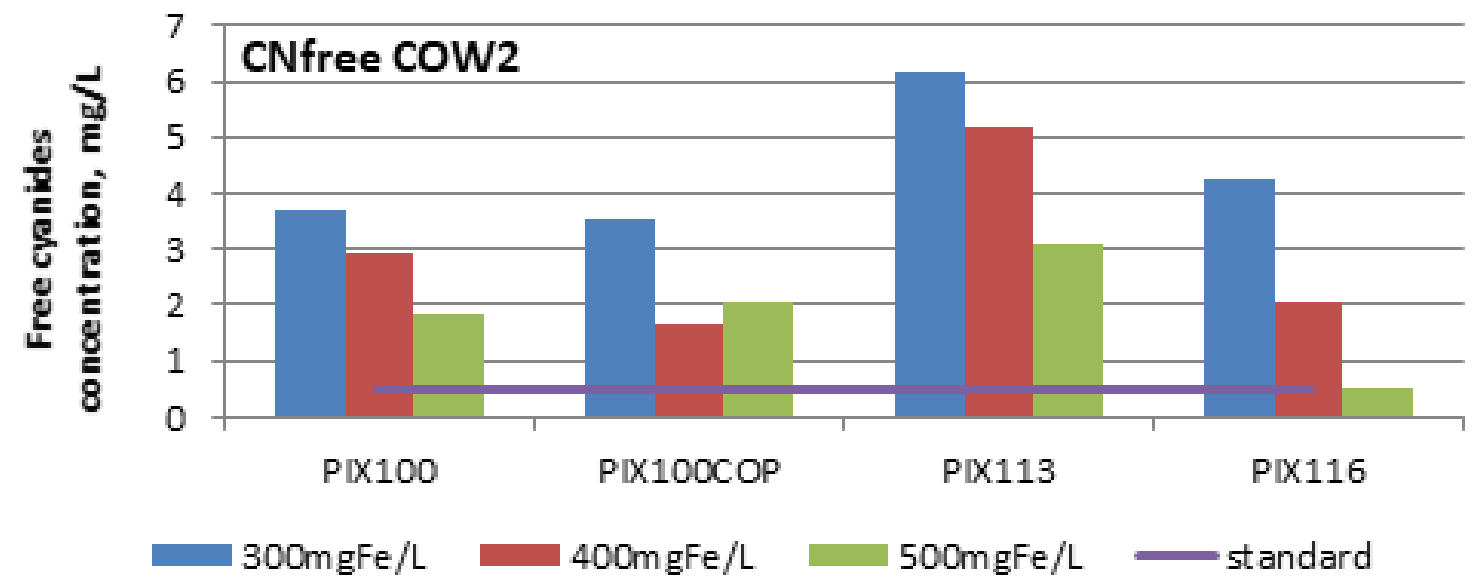

Figure 5: Final concentration of free cyanides in coke oven wastewater 2 (COW2).

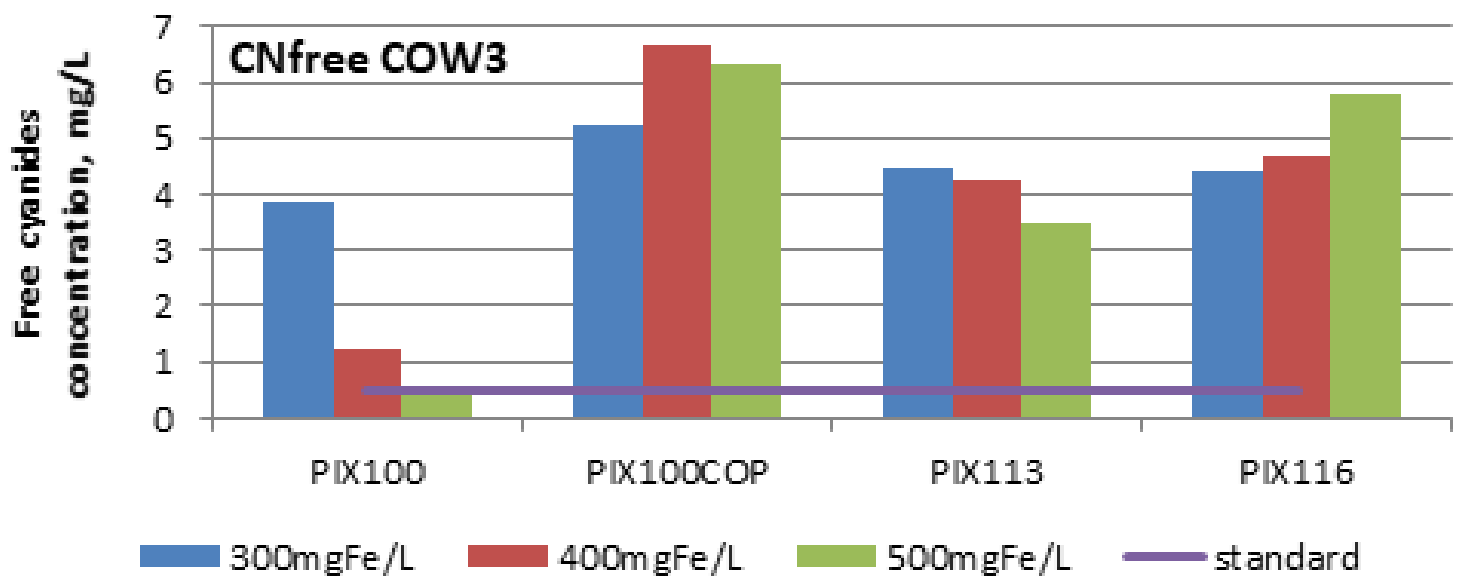

Figure 6: Final concentration of free cyanides in coke oven wastewater 3 (COW3). 


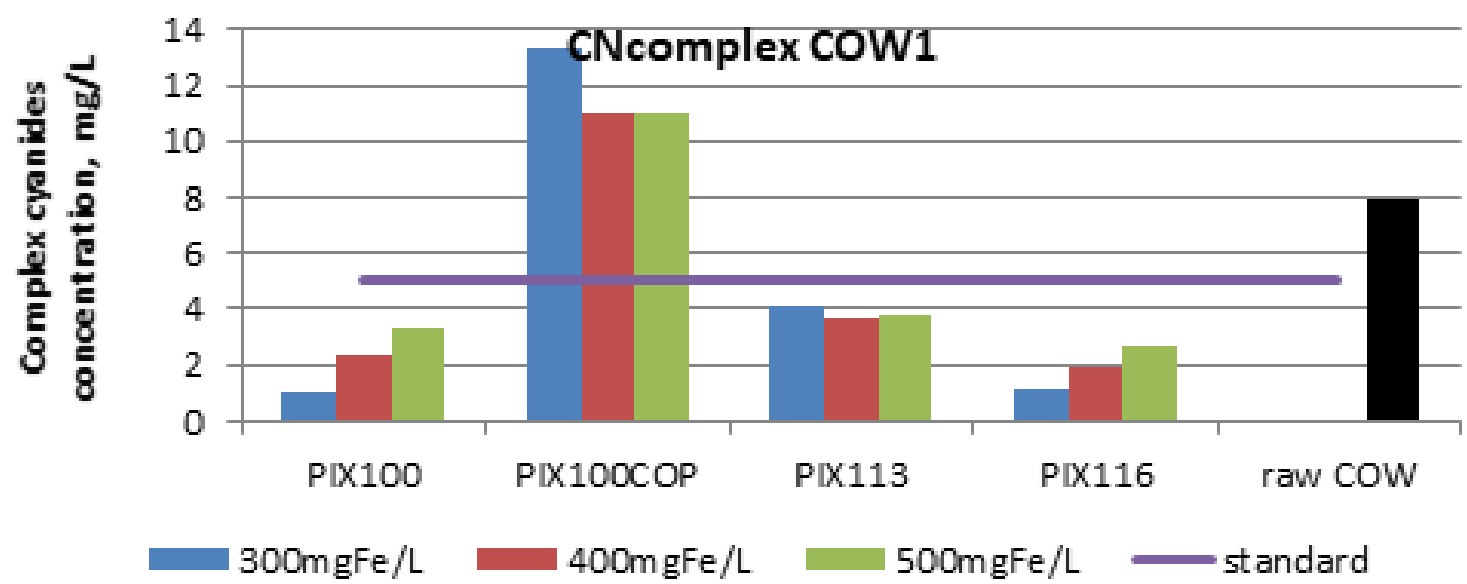

Figure 7: Final concentration of complex cyanides in COW1.

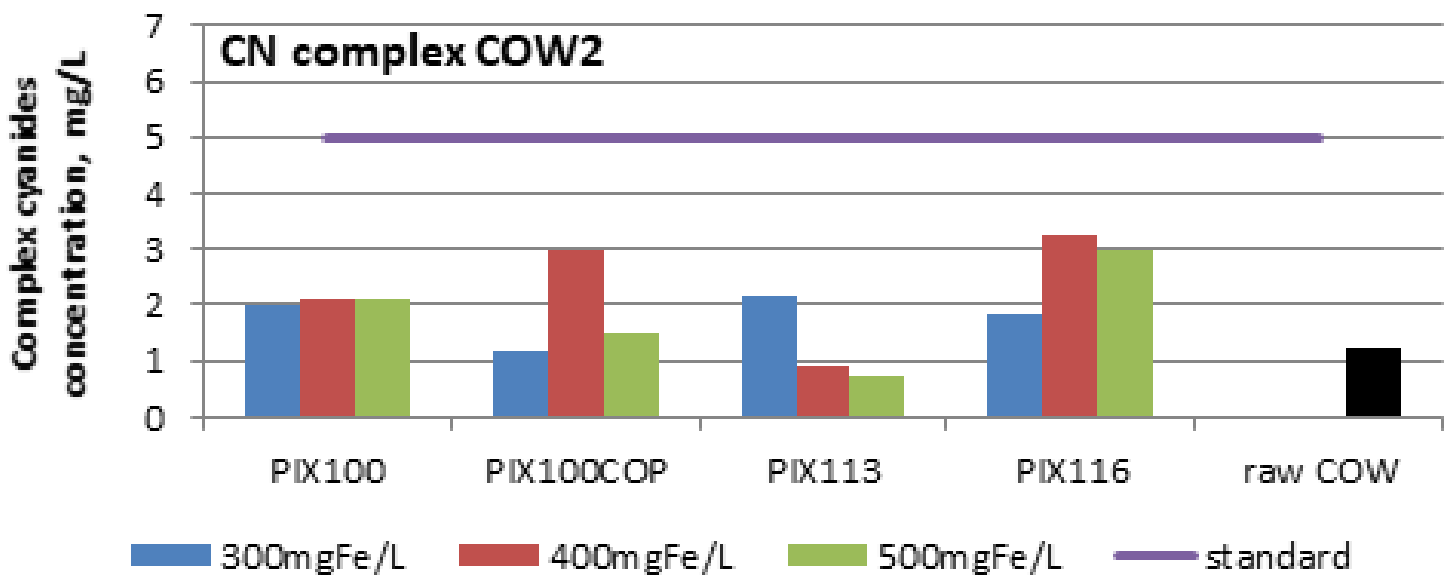

Figure 8: Final concentration of complex cyanides in COW2.

It was found that coagulation efficiency strongly depended on all considered process parameters, i.e. coagulant type, dose and coke oven wastewater properties and any relevant relationship between these parameters could not be found. It is a very important conclusion which suggests that coagulation/chemical treatment loop of every coke oven wastewater treatment plant should be recognized individually and coagulation process parameters should be selected on the basis of preliminary research. Among tested coagulants, PIX100COP most efficiently decreased free cyanides concentration in COW1 (Figure 4), when it was dosed in the amount of 400 and $500 \mathrm{mgFe} / \mathrm{L}$, while in case of COW2 PIX116 at dose of $500 \mathrm{mgFe} / \mathrm{L}$ was the most sufficient (Figure 5). The best treatment effect in COW3 was obtained for PIX100 coagulant (Figure 6).

\subsection{Complex cyanides removal}

In Figures 7-9 the impact of coagulant type and dose on the final concentration of complex cyanides in all treated coke oven wastewaters is shown. The standard, i.e. maximum complex cyanides concentration equal to $5.0 \mathrm{mg} / \mathrm{L}$ permitted for biological loop influent was established. Additionally, as complex cyanides appeared in the stream as a result of free cyanides complexation, the results were referred to initial concentration of the contaminant in the raw stream.

The best removal of complex cyanides was observed for COW2 for which the standard concentration $(5 \mathrm{mg} / \mathrm{L})$ was always obtained regardless of coagulant type or dose (Figure 8). It resulted from the relatively low concentration of the contaminant in raw stream $(1.2 \mathrm{mg} / \mathrm{L})$ and the effect 


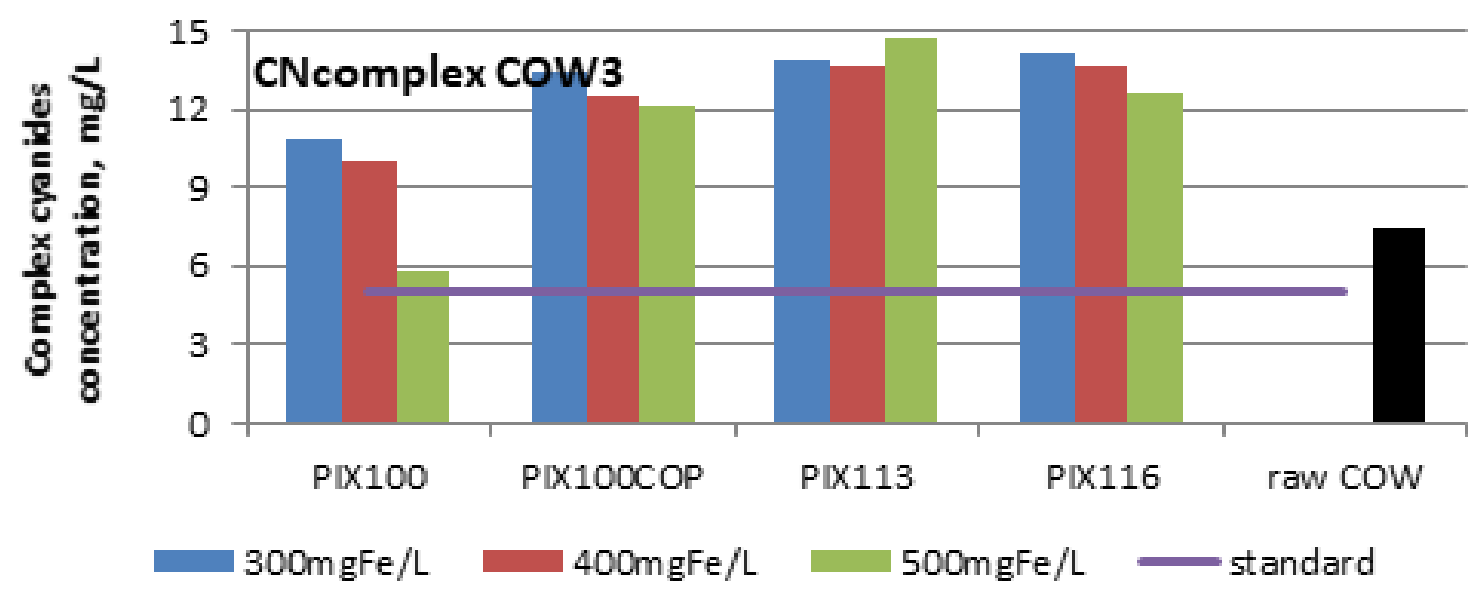

Figure 9: Final concentration of complex cyanides in COW3.

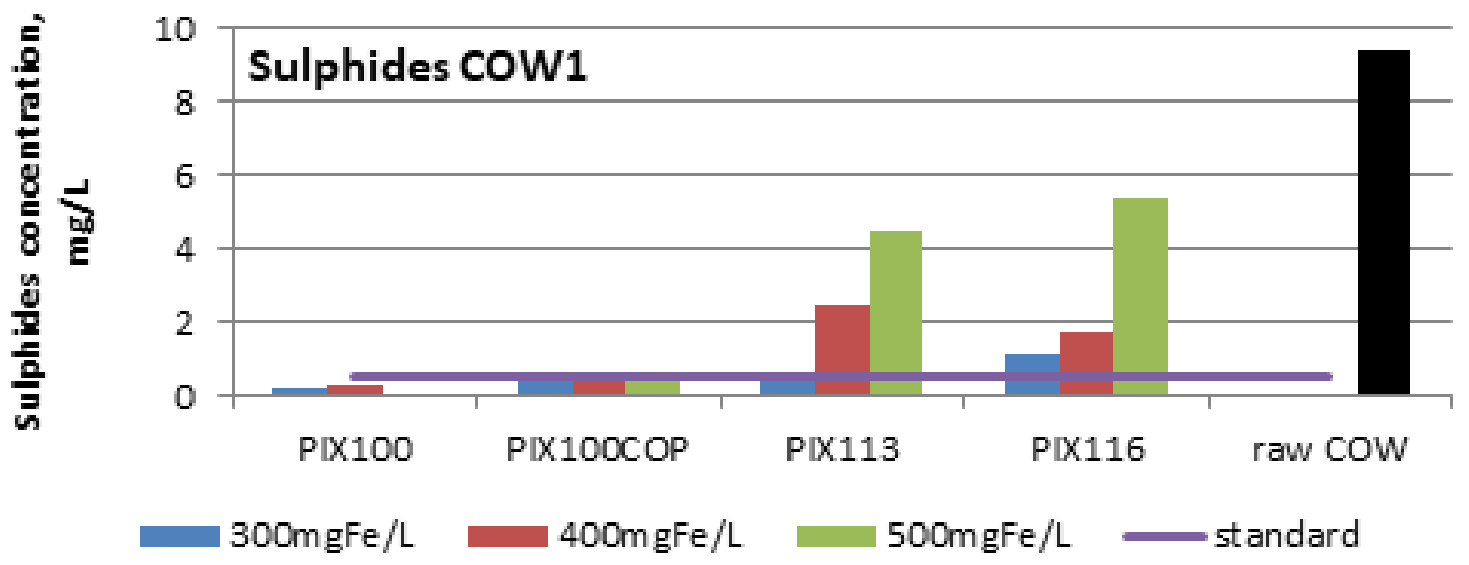

Figure 10: Final concentration of sulphides in COW1.

of $\mathrm{pH}$ discussed in chapter 3.4. On the other hand, the decrease in contaminant concentration in COW3 was very poor which was most probably related to the $\mathrm{pH}$ effect, as even after coagulant addition the wastewater remained highly alkaline (Figure 9). In the case of COW1, only the PIX100COP coagulant did not assure the required elimination of complex cyanides (Figure 7). Nevertheless, the conclusion from free cyanides removal efficiency was confirmed, i.e. the affinity of a wastewater to chemical treatment should be checked individually for a given wastewater.

\subsection{Sulphides removal}

In Figures 10-12 the impact of coagulant type and dose on the final concentration of sulphides in the tested coke oven wastewaters is shown. The same standard as for free cyanides, i.e. maximum sulphides concentration equal to $0.5 \mathrm{mg} / \mathrm{L}$ permitted for biological loop influent was established.

In the case of sulphide removal, better performance of ferrous coagulants was observed for COW1 and COW2, for which the permissible concentration or level close to it was obtained for both PIX100 and PIX100COP coagulants. On the other hand, the addition of ferric coagulants to COW2 resulted in the increase of sulphide concentration, even above their initial concentration in raw coke oven wastewater (Figure 11). Probably, ferric ions caused the decomposition of some sulphuric compounds present in the wastewater and free sulphides were revealed. In the case of COW3 the doses of all coagulants equal to 400 and $500 \mathrm{mgFe} / \mathrm{L}$ allowed for efficient sulphides concentration decrease with the exception of PIX100COP coagulant 


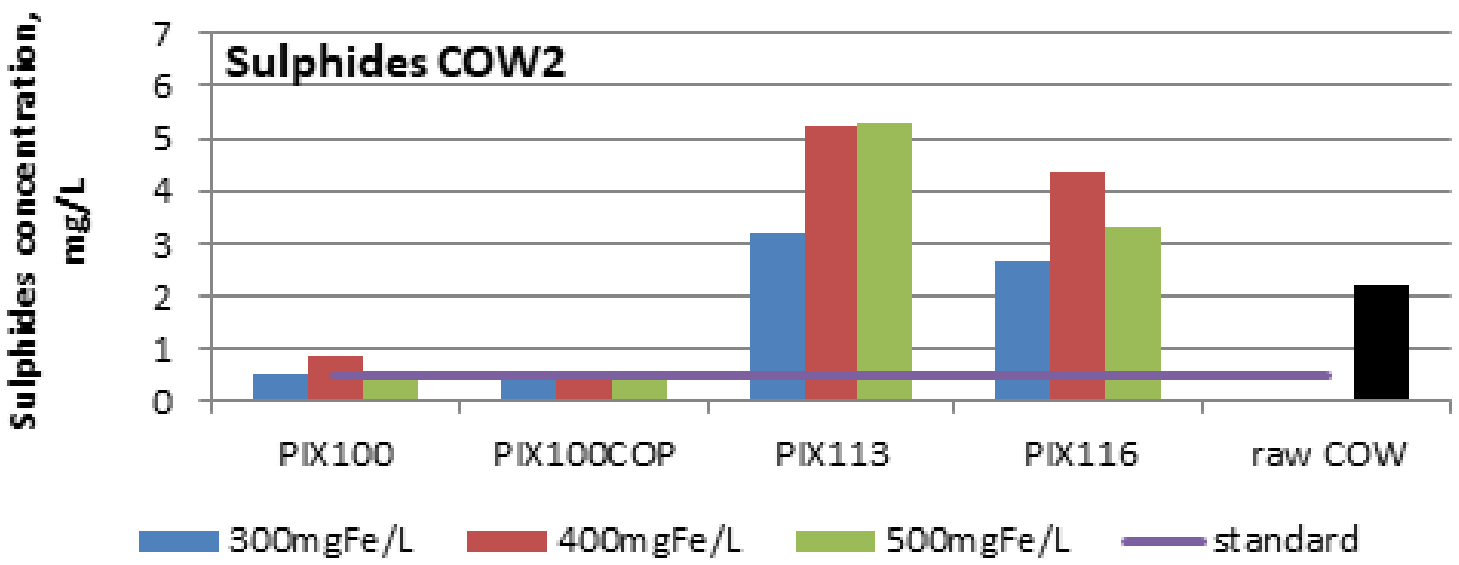

Figure 11: Final concentration of sulphides in COW2.

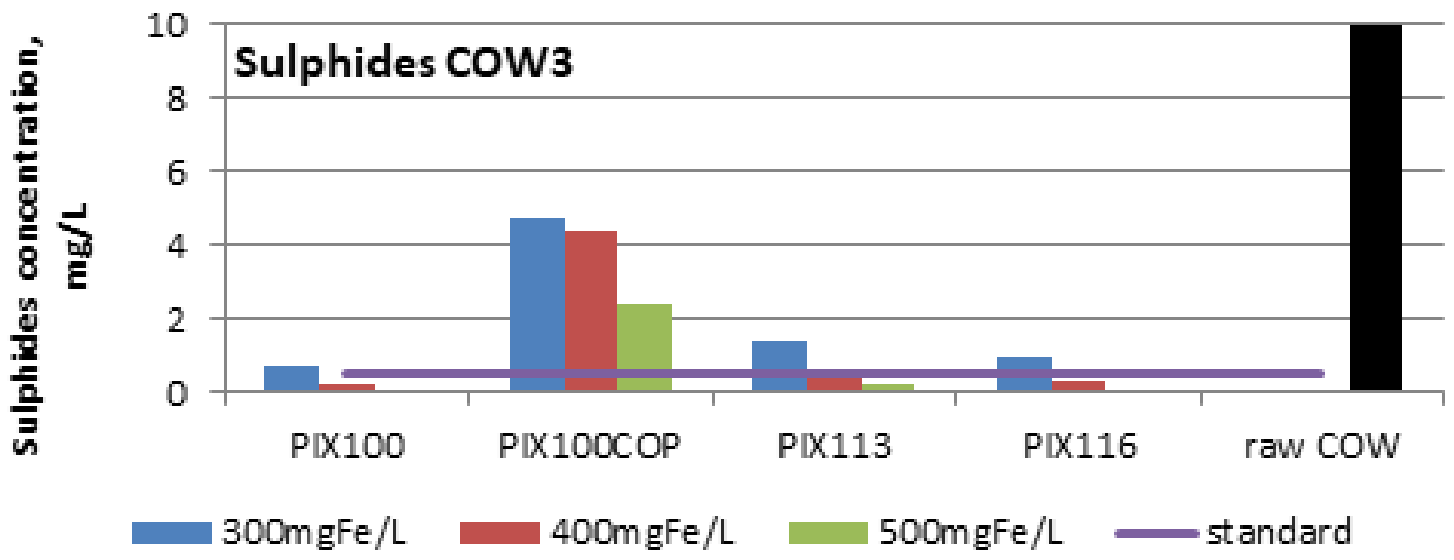

Figure 12: Final concentration of sulphides in COW3.

where the performance was not sufficient enough to effectively eliminate the contaminant from this watewater (Figure 12).

\subsection{Effect on COD, pH and salinity}

Coagulation, except for cyanides and sulphides removal, is also regarded as a process suitable for elimination of some organic compounds, which is accompanied by decrease of COD. Thus, in Figures 13-15 the effect of coagulant type and dose on COD removal rate is shown.

Surprisingly, it was observed that coagulation not only did not improve COD of coke oven wastewater but also, in many cases increased the parameter value and negative removal rates were observed. It was probably caused by reactions of ferric and ferrous ions with a number of compounds present in coke oven wastewater, which led to formation of compounds less vulnerable to oxidation.

Despite its treatment effect, coagulation is also known to cause both, $\mathrm{pH}$ decrease and salinity increase. Thus, in Figures 16-18 the impact of coagulant dose on wastewater $\mathrm{pH}$ is shown, while in Table 4 the increase of chlorides and sulphates concentration in regard to the respective coagulant dose is presented.

It was observed, that in general $\mathrm{pH}$ decreased with coagulant dose, however the final effect depended on coagulant type and the buffering capacity of wastewater. Hence, in COW1 and COW2 the pH decreased most significantly with ferric coagulant addition. On the other hand, the effect of dose was more noticeable for the ferrous coagulant PIX100 in case of COW2, while in case of COW1, 


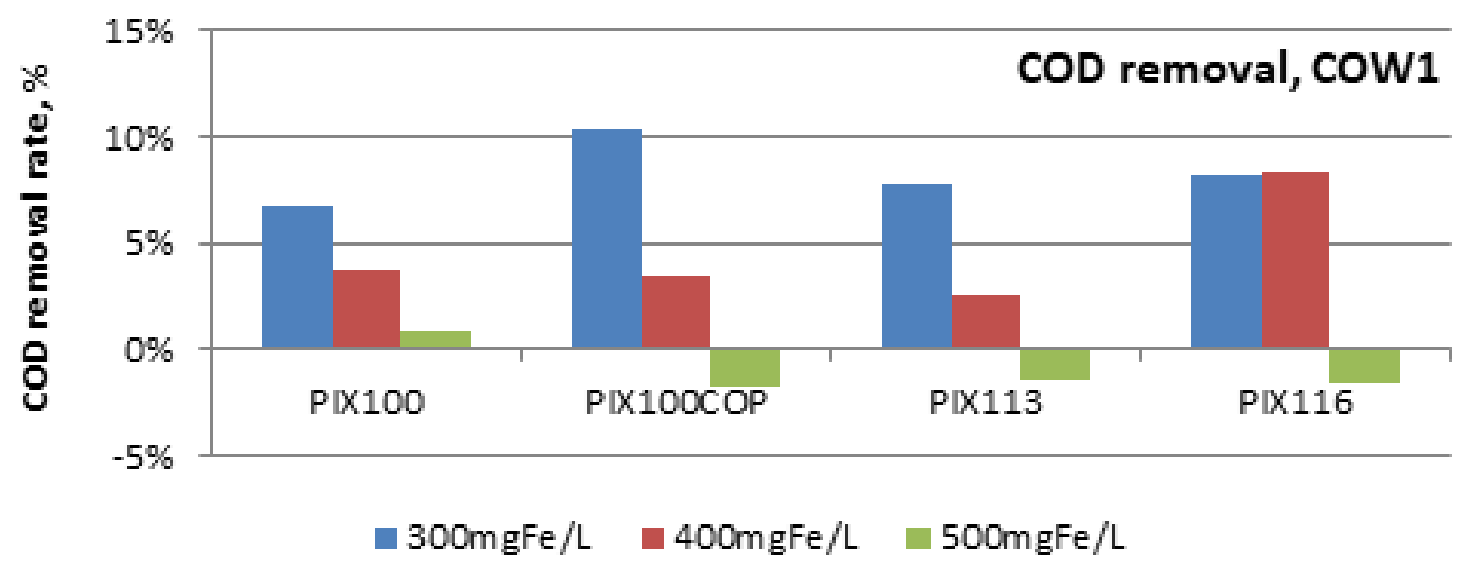

Figure 13: COD removal rate in COW1.

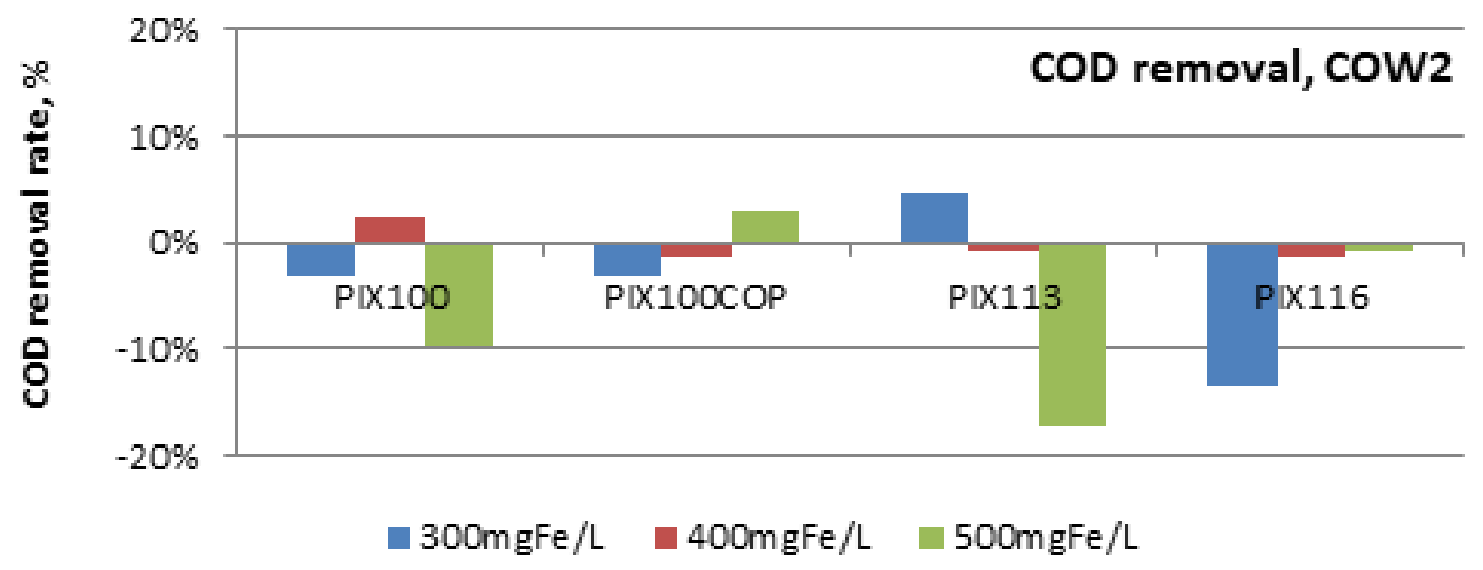

Figure 14: COD removal rate in COW2.

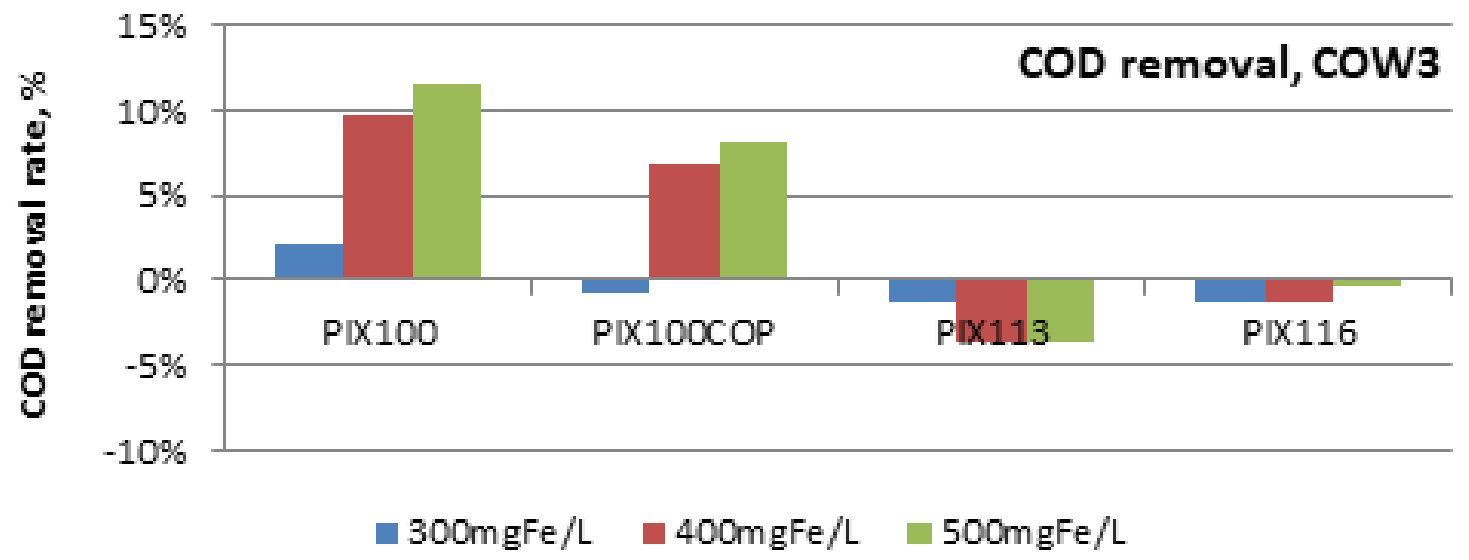

Figure 15: COD removal rate in COW3. 


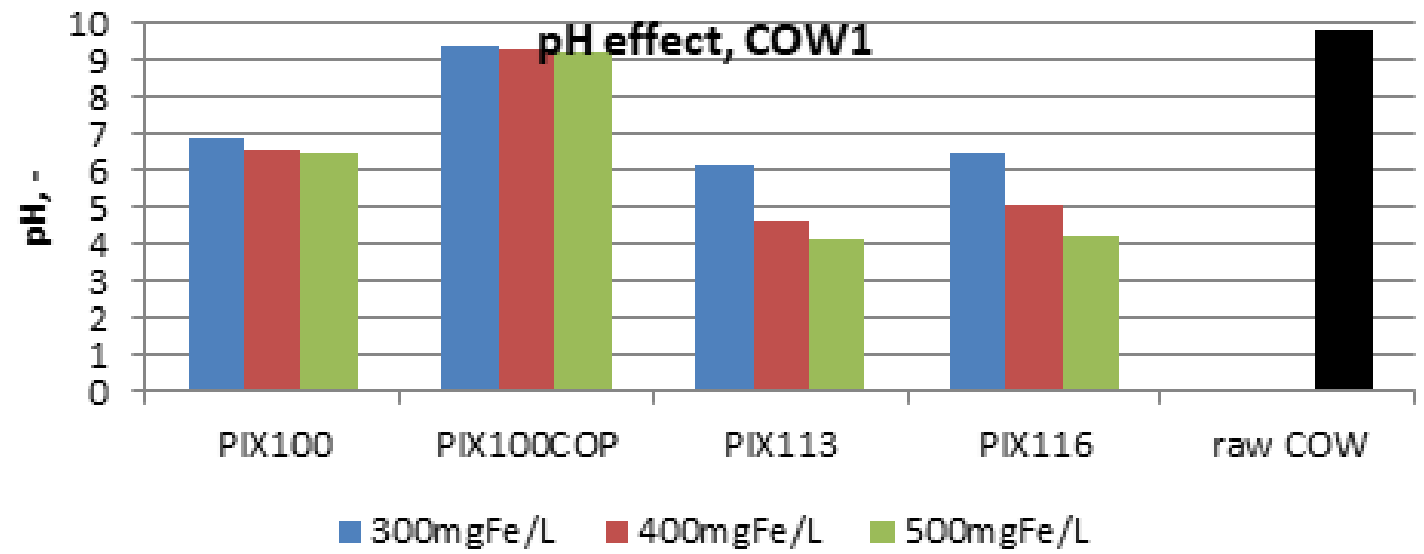

Figure 16: Effect of coagulant type and dose on pH of COW1.

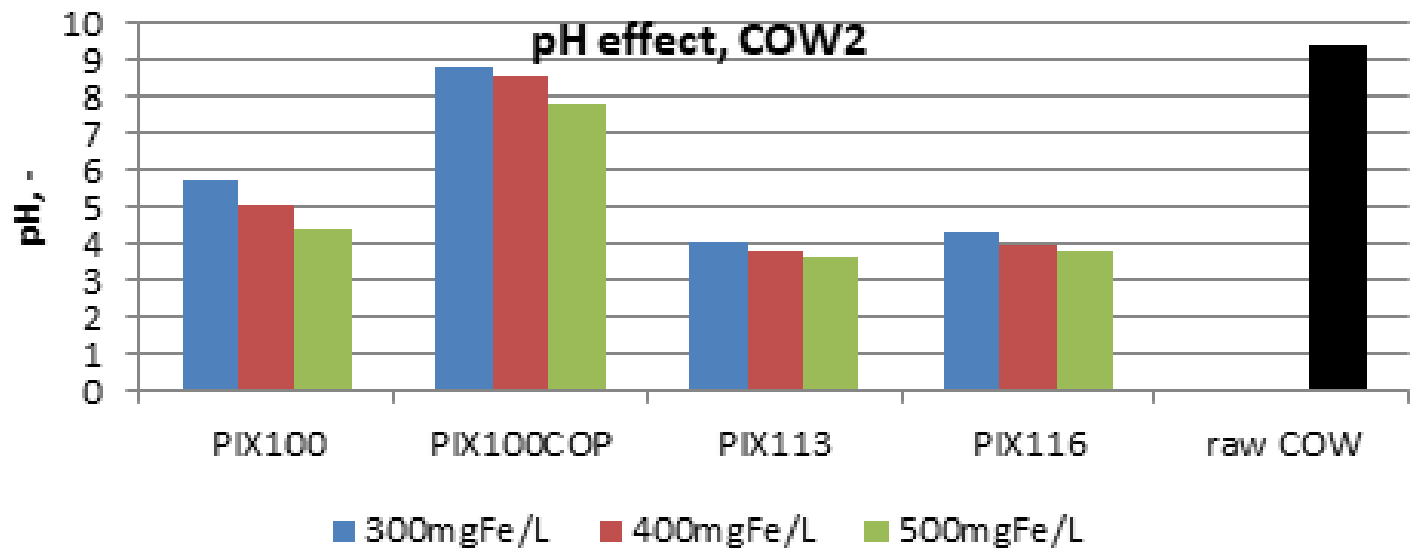

Figure 17: Effect of coagulant type and dose on pH of COW2.

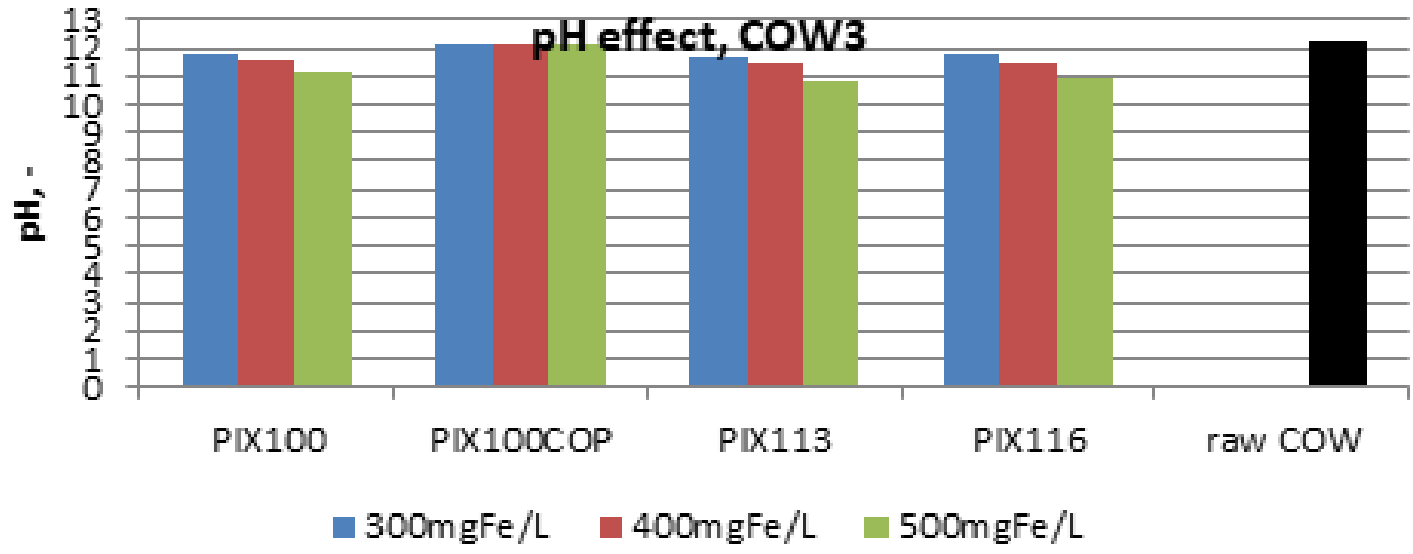

Figure 18: Effect of coagulant type and dose on pH of COW3. 
Table 4: Effect of coagulant addition on wastewater salinity.

\begin{tabular}{|c|c|c|c|c|c|c|}
\hline & \multicolumn{2}{|c|}{$\begin{array}{l}\text { Concentration in raw } \\
\text { wastewater, } \mathrm{mg} / \mathrm{L}\end{array}$} & \multicolumn{2}{|c|}{$\mathrm{mg}$ of $\mathrm{Cl} / 100 \mathrm{mg}$ of $\mathrm{Fe}$} & \multicolumn{2}{|c|}{$\mathrm{mg}$ of $\mathrm{SO}_{4}{ }^{2 \cdot} / 100 \mathrm{mg}$ of $\mathrm{Fe}$} \\
\hline & $\overline{\mathrm{Cl}^{-}}$ & $\mathrm{SO}_{4}^{2-}$ & PIX100 & PIX116 & PIX100COP & PIX113 \\
\hline Cow1 & 2,700 & 135 & 187 & 110 & 36 & 207 \\
\hline COW2 & 1,794 & 255 & 174 & 181 & 52 & 209 \\
\hline cow3 & 2,696 & 293 & 164 & 160 & 44 & 210 \\
\hline Average & 2,397 & 228 & 175 & 151 & 44 & 208 \\
\hline
\end{tabular}

increase in ferric coagulants dose more significantly influenced on the $\mathrm{pH}$ change. COW3, the most alkaline among all investigated wastewaters, was less susceptible to $\mathrm{pH}$ decrease. Finally, it was observed that PIX100COP coagulant affected coke oven wastewater $\mathrm{pH}$ to the lowest extent regardless of the stream type.

In the case of salinity it was found that chloride based coagulantsaffected the wastewater salinity in a comparable way and the amount of chlorides in wastewater increased by $175 \mathrm{mg} \mathrm{Cl} / 100 \mathrm{mg}$ of Fe in the case of PIX100 and by $151 \mathrm{mgCl} / 100 \mathrm{mg}$ of Fe for of PIX116. On the other hand, significant differences in salinity change were found for sulphate based coagulants. For PIX100COP, amount of sulphates introduced with coagulant was $44 \mathrm{mgSO}_{4}^{2-} / 100$ $\mathrm{mg}$ of Fe, while for PIX113 it was $208 \mathrm{mgSO}_{4}^{2-} / 100 \mathrm{mg}$ of Fe. In refer to raw coke oven wastewater, introduction of chlorides with coagulants resulted in $6-7 \%$ increase in their concentration per $100 \mathrm{mg}$ of Fe added, while in case of sulphate based coagulants, the anion concentration increased from 20 to $91 \%$ per $100 \mathrm{mg}$ of Fe added.

\section{Conclusions}

The research on the conventional coagulation process application to coke oven wastewater treatment resulted in very interesting conclusions. First of all, affinity of wastewater to treatment by means of coagulation should be checked for each wastewater type as removal of the process target contaminants, i.e. cyanides and sulphides, strongly depends on raw wastewater parameters. Therefore the coagulant type and dose has to be specifically selected. However, considering the valence of iron in applied coagulants, it may be concluded that ferrous based coagulants are more efficient in eliminating target contaminants than ferric ones. The desired effect of COD decrease is quite poor and in some cases a negative removal rate can be obtained. Coagulation always results in $\mathrm{pH}$ decrease, however the parameter affection depends on wastewater type and coagulant type, but this decrease is always greater with coagulant dose increase. Ferrous coagulants decrease the solution $\mathrm{pH}$ to a lesser extent than ferric ones. Finally, the overall salinity affection is less significant if chloride based coagulants are used, as the amount of chlorides in raw coke oven wastewater is much higher than the amount of sulphates. Thus, chloride based coagulants cause the increase in chlorides content below $10 \%$ per every $100 \mathrm{mg}$ of Fe added in refer to their initial concentration in the stream, while the addition of sulphate based coagulants changes sulphates content in the stream from 20 to $91 \%$ per every $100 \mathrm{mg}$ of Fe added.

Acknowledgements: The investigations in this paper were made within the INNOWATREAT project that has received funding from the Research Fund for Coal and Steel under grant agreement No 710078 and from Polish Ministry of Science and Higher Education from financial resources on science in 2016-2019.

Conflict of interest: Authors declare no conflict of interest.

\section{References}

[1] Remis R., Aguado Monsonet M.A., Roudier S. Sancho L.D., JRC Reference Report. Best Available Techniques (BAT) Reference Document for Iron and Steel Production. Industrial Emissions Directive 2010/75/EU (Integrated Pollution Prevention and Control), 2013. http://eippcb.jrc.ec.europa.eu/reference/BREF/ IS_Adopted_03_2012.pdf

[2] Bai X.F., Ding H., Lian J.J., Ma D., Yang X.Y., Sun N.X., Xue W.L., Chang Y.J., Coal production in China: past, present, and future projections, IntGeoRev, 2018, 60(5-6), 535-547.

[3] Sobolewski A., Bigda R., Telenga-Kopyczyńska J., Słowik K., Problems with determination of fugitive emission of polycyclic aromatic hydrocarbons from coke oven battery, JEcolEng., 2017,18(3),1-12.

[4] Tiwaria H.P., Sharmaa R., Kumar R., Mishrab P., Royb A., Haldarb S. K., A Review of Coke Making ByProducts, Coke and Chemistry, 2014, 57(12), 477-484. 
[5] Wright K., Coke oven gas treatment. Tar, liquor, ammonia. The coke oven manager's year book, 2001.

[6] Nomura S., Recent developments in cokemaking technologies in Japan, JFuProc., 2017, 159, 1-8.

[7] Razzaq R., Li C., Zhang S., Coke oven gas: Availability, properties, purification, and utilization in China, Fuel, 2013, 113, 287-299.

[8] Kwiecińska A., Lajnert R., Bigda R., Coke oven wastewater formation, treatment and utilization methods - A review, Proc. ECOpole, 2017, 11, 19-28.

[9] Pal P., Kumar R., Treatment of coke wastewater: A critical review for developing sustainable management strategies, Sep. Purif. Rev., 2014, 43, 89-123.

[10] Biswas J., Evaluation of various method and efficiencies for treatment of effluent from iron and steel industry-a review, IJMERR, 2013, 2(3), 67-73.

[11] Dyakov S. N., Chimarov V. A., Fritsler V. K., Manin N. S., Solodyankin S.S., Quality of Wastewater Sent for Biochemical Treatment, Coke and Chemistry, 2014, 57(2), 72-74.

[12] Hiao-xue W., Zi-yang Z., Qing-lan F., Xiao-ying Y., Dong-sheng $G$., The effect of treatment stages on the coking wastewater hazardous compounds and their toxicity, J. Hazard Mater., 2012, 2398(240), 135-141.

[13] Maranon E., Vazquez I., Rodriguez J., Castrillon L., Fernandez Y., Lopez H., Treatment of coke wastewater in a sequential batch reactor (SBR) at pilot plant scale, BioresTechnol., 2008, 99, 4192-4198.

[14] Ozyonar F., Karagozogly B., Treatment of pre-treated coke wastewater by electrocoagulation and electrochemical peroxidation processes, Separ Purif Technol., 2015, 150, 268277.

[15] Yu X., Xu R., Wei C., Wu H., Removal of cyanide compounds from coking wastewater by ferrous sulfate: Improvement of biodegradability, J.Haz.Mat., 2016, 302, 468-474,

[16] Jin X.,Li E., Lu S., Qiu Z., Sui A., Coking wastewater treatment for industrial reuse purpose: combining biological processes with ultrafiltration, nanofiltration and reverse osmosis, J.Environ. Sci., 2013, 25(8), 1565-1574.

[17] Jian S., He Z., Hongbin C., Yi Z., Yongsheng C., Removal of total cyanide in coking wastewater during a coagulation process: Significance of organic polymers, J Environ Sci., 2014, 26, 231239. 